\title{
España y sus castillos. La Guerra de Independencia y la iconografía romántica
}

\author{
LILY LITVAK \\ (The University of Texas at Austin) \\ Spain and its castles. \\ Independence War and romantic iconography.
}

RESUMEN ABSTRACT

En los primeros años del siglo XIX, España era considerada como un país atrasado, peligroso y fanático. Esta opinión cambió con la Guerra de Independencia (1808-1814). El levantamiento del pueblo contra el poderoso invasor francés ratificaba la idea romántica de la nación como ser vivo. La alianza con Inglaterra hizo que esa revalorización se llevara a cabo en ese país a nivel político, literario y artístico. La consideración de España como país romántico atrajo a muchos viajeros que descubrieron su herencia medieval y su pasado islámico, entre ellos a diversos pintores y dibujantes ingleses que en sus escritos, láminas y pinturas revelaron las bellezas monumentales de España.

PALABRAS CLAVE: Imagen de España, Romanticismo, Castillos
Before the Peninsular War, Spain was considered a backward, dangerous and fanatical country. The war, waged by the Spanish people against the powerful French invader, revealed a different image, and confirmed the Romantic idea of a nation. In England this reconsideration was political, literary and artistic. The reputation of Spain as the archetypal Romantic country attracted many travelers that discovered Spain's magnificent Medieval and Islamic heritage.Amongst them were several British artists who in their work revealed Spain's monumental treasures.

KEYWORDS:

Spain's image,

Romanticism, Castles

José Zorrilla dedicó a Jenaro Pérez Villaamil su poema «La noche de invierno» (1837). Se inicia exhortando al pintor para que prepare lienzo y pinceles para pintar unos cuadros que serán el motivo de inspiración del poeta. A continuación, Zorrilla consagra varios versos a los temas que constituirían los paisajes de Villaamil: el viento, la lluvia, la montaña, el huracán en la noche, y un nutrido catálogo de motivos arquitectónicos: torres, castillos, ciudades almenadas, alcázares morunos, palacios, gabinetes cincelados de la Alambra. 
No fue Zorrilla el único ecritor romántico español que acudió a ese tópico, también lo hicieron, entre muchos otros, Carolina Coronado en el «Castillo de Salvatierra,» Espronceda en El estudiante de Salamanca, Hartzenbusch en Los amantes de Teruel, y se debe mencionar a Bécquer, quien a menudo ambienta sus leyendas en castillos. Este paisaje con la vista de uno o varios monumentos; muralla, fortaleza, castillo, torre, llegó a ser un tópico europeo de la figuración de España en el siglo XIX. ${ }^{1}$

Anteriormente, estas imágenes había sido utilizado por algunos artistas, entre ellos el francés Houasse que organizó sus vistas alrededor de los palacios, y Antonio Joli, invitado a pintar por los monarcas. Sin embargo, fue durante el Romanticismo cuando esa iconografía se convirtió en emblema de la historia y cultura de España, con significaciones de caballerosidad, lealtad, valentía y devoción a la religión.

El concepto adquirió popularidad con la Guerra de Independencia, (1808-1814). Anteriormente, el país se consideraba pobre, peligroso, atrasado, y como herencia de la leyenda negra, bastión del más fanático catolicismo. La contienda, sin embargo, reveló otro rostro de España. El levantamiento del pueblo que se había batido implacablemente contra el poderoso invasor ratificaba la idea romántica de la nación como ser vivo. Era asimismo romántico el espíritu que mantuvo el esfuerzo de los españoles, visible tanto en el tradicionalismo popular, no solo literario, sino de costumbres, carácter y sentimiento, así como en el liberalismo de los oradores de las Cortes de Cádiz más radical que el de los ministros del despotismo ilustrado de Carlos III.

En Inglaterra esa revalorización fue en gran parte debida a la Guerra de Independencia o Peninsular War. En la contienda contra Napoleón ambos países se encontraron unidos después de siglos de enemistad. La creciente importancia de España para la política exterior de Gran Bretaña, abrió un nuevo espacio en el discurso militar y económico; el frente rompió el bloqueo continental y contribuyó a aliviar la crisis económica británica al abrir los puertos españoles e iberoamericanos al comercio. La unión trasformó en fascinación los prejuicios negativos. Henry Gally Knight en su Iberia's Crisis, (1809), comentaba que: «España se ha vuelto importante para todo el mundo, porque en la actual crisis da un memorable ejemplo a toda Europa, al luchar por sus libertades y derechos contra el inescrupuloso usurpador extranjero". ${ }^{2}$

El fervor patriótico promovió un vínculo entre lo histórico, lo político, lo artístico y lo literario. España penetró en la vida británica, exaltada en los poemas dedicados a las victorias de Wellington y en odas por la muerte de Sir John Moore. Sir David Wilkie, que llegó a Madrid en 1827 describió apasionadamente la guerra. Lo había seducido el heroísmo del pueblo, el hecho de que no había sido un ejército sino

1 Sobre este tema véase, SAGLIA Diego, Poetic Castles in Spain: British Romanticism and Figurations of Iberia, Amsterdam, Atlanta Ga., Rodopi, 2000, y Sarah Symmons, «Castles in Spain: Romantic tourists and literry landscapes", Romantic Geographies, Glasgow, University of Glasgow French and German Publications, 1996,137-147 y José ALBERICH, Imagen Romántica de España, Catálogo Exposición, Madrid, Ministerio de Cultura, 1981.

2 Saglia Diego, Op. cit., 11. 
bandas de guerrilleros dirigidos por héroes populares como «El Empecinado», «El Médico», Julián Sánchez, y otros más, quienes habían hostigado sin tregua a los franceses. Planeaba ejecutar algunos cuadros que celebraran la «Spanishness» (españolidad), y quería que figurara como protagonista la «guerrilla» ${ }^{3}$. El más conocido es The Defense of Saragossa, $(1829)^{4}$ donde Wilkie proponia una nueva iconografía del heroísmo inspirada en Byron. La obra alude al legendario momento en que Agustina de Aragón, la «Spanish maid», como la llamó Byron, se prepara para encender la mecha del cañon que don José de Palafox ayuda a dirigir contra el enemigo. ${ }^{5}$ El padre Consolación señala el blanco con su crucifijo, y Boggiero, el religioso, orador y poeta italiano, que participó en los dos sitios de Zaragoza, escribe el despacho que deberá ser enviado con la paloma mensajera. La portada de la iglesia enmarca y protege a los protagonistas que a su vez la defienden ${ }^{6}$.

1.- Sir David Wilkie, The Defense of Saragossa, 1829, The Royal Collection,

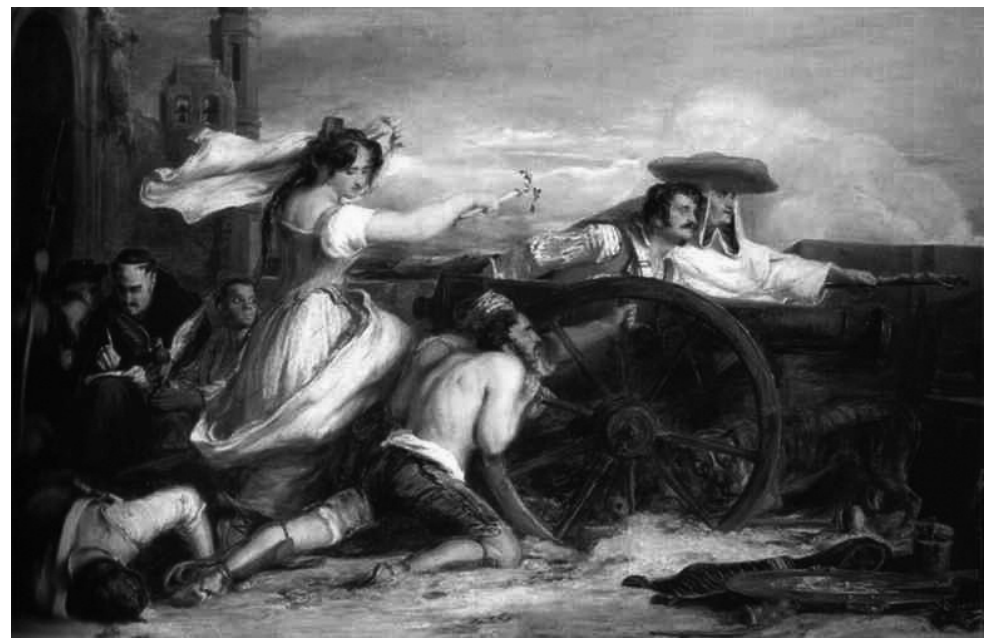

National Galleries of Scotland, Edinburgo.

3 Wilkie pintó cuatro cuadros con ese tema; The Defense of Saragossa, The Spanish Posada, con tipos regionales en un consejo de Guerra, Guerilla's Departure, con un cura que despide a un campesino que va a pelear, The Guerilla Return. Véase al respecto, Nicholas Tromans, "The Age of Goya», en Christopher Baker, The Discovery of Spain. British Artists and Collectors, Edinburgh, National Galleries of Scotland, 2009, 29-46.

4 Edinburgo, The Royal Collection. Goya había hecho una imagen menos dramática del acontecimiento; Qué valor!, lámina 7 de Los Desastres de la Guerra. (1809-14).

5 Canto I de Byron, Childe Harold's Pilgrimage. A Romaunt, Cantos I and II, London, 1812.

6 Palafox posó para este cuadro. El episodio se produjo ante la iglesia del Portillo, situada entonces muy cercana a una de las puertas de la muralla zaragozana. Sin embargo, la iglesia del cuadro no parece ser el campanario de la Seo (El Salvador), ni puede ser la torre del Pilar, que entonces no había sido levantada. No se asemeja a la Torre Nueva, mudéjar e inclinada, que era entonces el monumento más famoso de Zaragoza, y que fue derribada a fines del siglo XIX. El edificio es simbólico; rudo, sin decoraciones, recuerda la arquitectura gótica por su impulso ascendente, y posee un cierto organicismo; una asimilación a la piedra o al tronco de un árbol. El famoso cuadro de Delacroix, La Liberté guidant le peuple (1830), toma algunos temas de esta obra. 
La guerra consagró a España como país romántico por excelencia. Muchos escritores y artistas la colocaban a la par con Italia y Grecia, y era inclusive más interesante, pues fueron los mitos culturales de la antigüedad los que calificaron a estos dos países, mientras que el interés por la península había sido determinado por acontecimientos de vivísima actualidad. Robert Southey lo confirmaba en su History of the Peninsular War (1823-28), así como Byron, el más famoso de los viajeros ingleses en el canto I de Childe Harold's Pilgrimag: «Oh Lovely Spain, Renowed, Romantic land». ${ }^{7}$

Los atractivos que ese territorio casi inexplorado ofrecía eran muchos. El momento de la resistencia contra Napoleón está ligado a las ficciones exotistas y a la moda medievalizante. El romanticismo descubrió la edad media española, así como su fecundo pasado árabe, cuyas huellas eran visibles en su gente y su paisaje lleno de castillos y torreones, de palacios y mezquitas. Producto temprano de ello fueron las obras británicas sobre el último rey visigodo Don Rodrigo o Don Roderick, por Walter Scott, Landor y Southey, escritas entre 1811 y 1814 y aquellas inspiradas por la Alhambra: Alcon Malanzore de Eliza Norton, (1815), The Abencerrage (1819) de Felicia Heman, The Moor (1825) de Lord Porchester.

\section{VIAJE A LA ESPAÑA ROMÁNTICA}

El rechazo del clasicismo y la valoración de lo desconocido, de lo exótico e irracional, indicaba el camino hacia España, un país primitivo, sin señas de industrialismo, que ofrecía la promesa de nuevas sensaciones. Asi lo aseguraba Richard Ford, convencido de que al atravesar los Pirineos, se dejaba atrás el aburrimiento, la monotonía de la civilización». ${ }^{8}$

Todavía en 1776 Voltaire había descrito a ese país como periférico, tan misterioso como Africa e impenetrable para los viajeros, y si bien en el siglo XIX, el trayecto era aún muy difícil y peligroso, representaba una alternativa para quienes buscaban salir de la trillada ruta del grand tour. Washington Irving, que permaneció en España entre 1826 y 1828, comentaba con admiración que allí «la más miserable choza está tan llena de aventura como un castillo encantado...» y exhortaba al viajero: «dejad que otros se quejen por la falta de caminos y de hoteles suntuosos y de las elaboradas comodidades de algún otro país que de tan cultivado y civilizado ha quedado domesticado y convertido en un lugar común. Dadme en cambio las montañas, las sendas estrechas y sinuosas, las costumbres, medio salvajes pero francas y hospitalarias, que imparten sabor a la querida y romántica España». ${ }^{9}$

7 Sobre el tema de Byron y España, véase SAGLIA Diego, Byron and Spain: Itinerary in the Writing of Place, Lewiston, NY., Edwin Mellen Pr., 1997.

8 FORD Richard, Hand-Book for Travellers in Spain (1845), cit. de la edición, de Centaur Press, Fontwell and London, 1966, 118, y 171,

9 SAGLIA, Poetic Castles, 47. 
La fama romántica de España coincidió con la boga de la literatura de viajes que produciría una extensa e intensa bibliografía. ${ }^{10}$ La nómina de escritores y artistas viajeros es amplísima, así como la variedad de intereses de cada uno de ellos. Y no solo eran ellos quienes conocían esos nuevos lugares, sino que a través de sus publicaciones permitían al lector el compartir sus experiencias sin moverse del sillón de su casa. Se debe mencionar además, que como consecuencia de la guerra, la península fue recorrida por muchos soldados y oficiales que más tarde, de viva voz o en letra impresa, hablarían de las bellezas alli encontradas. Aún años después de Waterloo las relaciones hispano británicas continuaron y la agitada historia española atravesada por las guerras carlistas, las disputas entre conservadores y liberales, rebeliones y pronunciamiento, formó el telón de fondo para los trayectos de hispanófilos victorianos como Richard Ford, David Roberts, George Borrow, Sir David Wilkie, Alfred Tennyson.

El libro de Alexandre Laborde, Voyage pitoresque et historique de l'Espagne, publicado entre 1806 y 1820, fue, de hecho, la primera guía de viajes por España y es de señalar la publicación en su momento de una edición inglesa, otra española y otra alemana, lo cual pone de relieve el impacto y la fortuna de esa obra, inscrita en el contexto de la consolidación de la literatura de viajes. Aunque el autor era favorable a Napoleón, hacía notar que España llegaría al gran esplendor al que fue destinada, por su situación, sus riquezas naturales y las grandes cualidades de sus habitantes. ${ }^{11}$ La obra constaba de cuatro volúmenes, ilustrados con 349 grabados de gran calidad, elaborados por un equipo de artistas y dibujantes, entre los que sobresalieron Jacques Moulinier y François Ligier. Incluía además de la descripción de los monumentos antiguos, fruto de la admiración de Laborde por la tarea unificadora de Roma, los capítulos correspondientes a la época medieval, con indicaciones minuciosas sobre conjuntos urbanos, castillos, fortalezas, pueblos pintorescos, y desplegaba en la página titular un magnífico paisaje con unas torres perfiladas en la distancia.

\section{CUATRO ARTISTAS BRITÁNICOS Y UN PINTOR ESPAÑOL EN LA ESPAÑA ROMÁNTICA}

La incorporación de la Península Ibérica a las rutas europeas de viajeros supuso el descubrimiento del paisaje, interpretado como un palimpsesto de historia

\footnotetext{
10 Sobre este tema DÍAZ LÓPEZ Juan Antonio, «Modelos literarios y estéticos de los viajeros románticos ingleses. De la teoría a la praxis, 85-94, Fco. Calvo Serraller, «Oriente y la voluntad de expresión romántica», 139-144, MARI Antonio, «Los viajeros románticos franceses y el mito de España», 145-150, todos en La imgen romántica del legado andalusí, Madrid, Lundwerg Editores, 1995, Léon François Hoffmann, Romantique Espagne. L'Image d'Espagne en France entre 1800 et 1850, Paris, 1961.

11 El estallido de la guerra en España, en 1808, comprometió la finalización del proyecto que había nacido con la ayuda tanto del rey de España como del Gobierno francés. La guerra comportó la ruina de Laborde, que se vio obligado a pagar con su propia fortuna la realización final del libro. Después, la caída del imperio retrasó aún más su publicación, que se prolongó catorce años, de 1806 a 1820 .Véase El viaje a España de Alexandre de Laborde, el catálogo de la Exposición organizada por el Museu Nacional d'Art de Catalunya Del 29 de mayo al 27 de agosto de 2006, Francesc Quílez y Jordi Casanovas, Barcelona, MNAC, 2006.
} 
nacional, arquitectura, y elementos geográficos, culturales y folklóricos. Atraía su terreno rugoso, escarpado y difícil, su vegetación mediterránea, los antiguos pueblos y ciudades y sobre todo, coronando el agreste panorama, los imponentes edificios que rememoraban una gloriosa y aguerrida edad media; murallas, torreones, fortalezas y castillos, que contribuyeron a fijar la imagen de España en el mapa del romanticismo, tan lleno de deseos y de sueños como de realidades.

Se exaltaba la ciudad antigua; Toledo, que mantenía viva la huella del pasado con monumentos como el alcázar, que parecía «uno de esos sueños de arquitectura». La maurofilia convirtió a Andalucía en región favorita; Sevilla, y Córdoba, «no tienen rival en Europa», Granada era «legendaria», «sacada de las mil y una noches», Ronda caló en el corazón de Ford: «No hay más que una Ronda en todo el mundo, ...y ese cañón cortado por el río y su cascada constituyen su corazón y su alma. El sonido y movimiento de la escena desafían a la pluma y al lápiz». ${ }^{12}$ Esos temas, reforzados por la literatura de Cervantes y el «descubrimiento» del Romancero propiciaban la imagen difundida por la guerra: un país altivo y heroico, indómito y finalmente victorioso. Muchos artistas británicos viajaron y describieron esas imágenes, ${ }^{13}$ y por ser imposible referinos a todos o incluso a una mayoría de ellos, a continuación se analiza la obra de cuatro que son reprentativos de la pasión que ese país romántico había despertado.

El militar y dibujante Edward Hawke Locker, arrivó a las costas de Tarragona durante la Guerra de la Independencia, en junio de 1813, como secretario del almirante Sir Edward Pellew en la flota del Mediterráneo. ${ }^{14}$ En marzo de ese año José Bonaparte abandonaba Madrid, y en su retirada hacia Francia, tras ser derrotado en Valladolid, se vió forzado a refugiarse en Pamplona. Locker, acompañado por John Russell, que a mediados de siglo sería primer ministro de Inglaterra, partió el 3 de octubre hacia el Norte para entregar unos despachos confidenciales a Wellington recién llegado a Vera de Bidasoa. Dejaba atrás una Tarragona casi totamente destruída y en el peligroso trayecto debía eludir las plazas y los caminos reales aun dominados por los franceses.

El trayecto duró 55 días y Locker, que era un excelente dibujante y acuarelista y viajaba siempre con lápices, pinceles, una libreta de apuntes y un diario, tomó notas y dibujos de las ciudades, pueblos, monumentos y paisaje. Las peculiares circunstancias de su itinerario le ofrecieron la oportunidad de incorporar esbozos de pequeños pueblos, aldeas y caseríos de poca importancia, fondas y posadas,

12 FORD, Op. cit., 34 y 100.

13 ALBERICH José, Del Támesis al Guadalquivir, Antología de viajeros ingleses en la Sevilla del s. $X I X$, Sevilla, Universidad de Sevilla, 1976. Ian Robertson, Los curiosos impertinentes. Viajeros ingleses por España desde la ascensión de Carlos III hasta 1855, Barcelona, Ediciones del Serbal, 1988.

14 Véase «CABRA LAREDO María Dolores: «Una visión innovadora de la Guerra de Independencia: Edward Hawke Locker», Goya: Revista de Arte, No. 181-82, 1984, 75-79, de la misma autora prólogo a Views in Spain, Madrid, El Museo Universal, 1984, FREIXÁ, C., «Paisajes de España: entre lo pintoresco y lo sublime», Estudio introductorio, Views in Spain, Barcelona, Ediciones del Serbal, 1998. 
ruinas, viejos puentes, pintorescos ríos, castillos e iglesias, y de contemplar y meditar sobre diversos aspectos de la forma de vida de la gente.

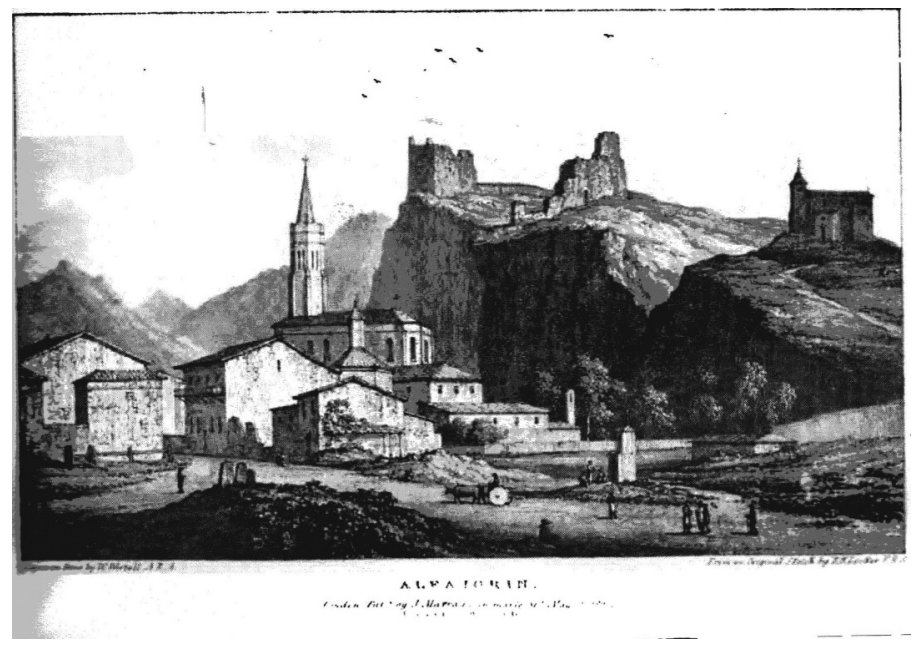

2.- Edward Hawke Locker, Aljaforín, Views in Spain, London, John Murray Albemarle Street, 1824, lam. 9.

Evitando Lérida, Locker pasó por Reus y Alforja. Saliendo de Fraga, donde presenció de primera mano las consecuencias de la brutalidad de los franceses, se detuvo en Aljaforín un bello paraje coronado con las ruinas del majestuoso castillo sobre la montaña. Ilustró su llegada a Zaragoza, con una lámina del «Puente sobre el Ebro» y sus comentarios sobre la heróica defensa de los españoles. Indica que se detuvo a cada paso para inspeccionar el lugar y verificar los estragos que la guerra había causado. Muy cerca de Pamplona, aún temiendo el ser sorprendido y tomado prisionero, no pudo resistir la tentación, y se arriesgó a dibujar el magnífico panorama. Presenta en primer plano a un grupo de personas conversando, y al fondo la ciudad amurallada. Sorpresivamente, el contorno se encuentra salpicado de construcciones de estilo arábigo que según Eduardo Morales Solchaga no se corresponden con la realidad. ${ }^{15}$ Saliendo de Ernani pasó por Villabona, entonces ocupada por una brigada inglesa, pero se detuvo para captar el antiguo puente de tres arcos sobre el Orrea y los castillos sobre las rocosas montañas. Después de entregar los documentos a Wellington, se dirigió a Irún, Fuenterrabia y San Sebastián, que había sido saqueada. Desde Madrid, donde estuvo un corto tiempo visitó Toledo, e inspirado por su gran admiración por Don Quijote pasó por ciertos pueblos de la Mancha, incluyendo el Toboso.

\footnotetext{
15 Eduardo Morales Solchaga, «Vista de Pamplona», www.unav.es/.../vistadePamplona/default.html.
} 


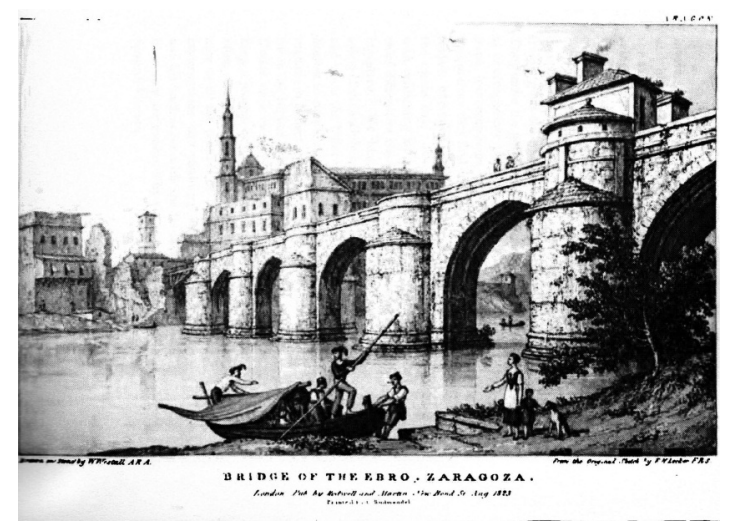

3.- Edward Hawke Locker, Bridge of the Ebro. Zaragoza, Views in Spain, lam.10.

De vuelta en Londres, a comienzos de 1823, cuando se anunciaba la intervención en España de los «cien mil hijos de San Luis», Locker empezó la adaptación litográfica de sus impresiones y acuarelas, acudiendo para ello al prestigioso artista y grabador William Westhall, miembro de la Royal Academy. Views in Spain se publicó por entregas durante más de un año y en 1824 se editó como libro con sesenta grabados, algunos son fruto del viaje comentado, y otros realizados con anterioridad. En su dedicatoria a Russell, Locker hace un recuento de sus sentimientos hacia España y muestra su indignación por esa segunda invasión. La obra tuvo gran éxito sobre todo por las magníficas láminas, muchas de las cuales se vendían por separado para ser enmarcadas.

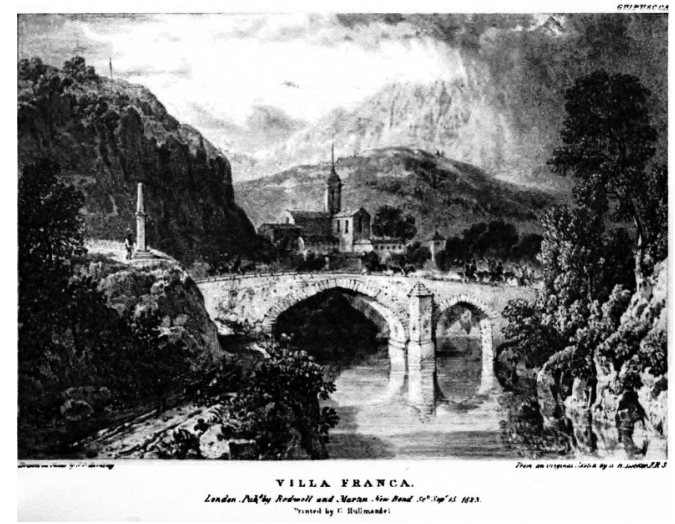

4.- Edward Hawke Locker, Villafranca, Views in Spain, lam. 29.

Otro interesante viajero fue Richard Ford, el autor de la primera guía británica; Hand-book for Travellers im Spain and Readers at Home (1845). Llegó a España con su mujer Harriet y sus tres hijos pequeños en 1830 y se quedó hasta 1833. Pa- 
saba los inviernos en Sevilla y los veranos en la Alhambra, y se dedicó a viajar extensamente, dibujando paisajes, tomando notas, y coleccionando obras de arte español. ${ }^{16}$ Esa afición y sus considerables conocimientos se reflejan en los comentarios del Handbook.

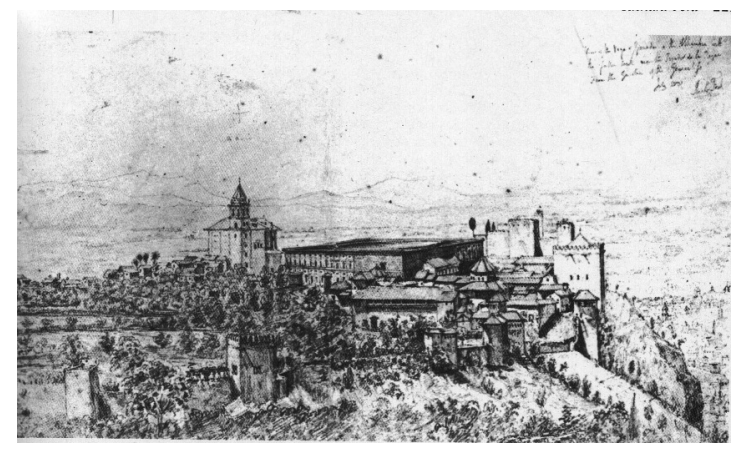

5.- Richard Ford, La Alhambra desde el Generalife.

A su llegada a Sevilla, Ford solía lanzarse diariamente a la calle, y deambulaba por la ciudad, examinando su arquitectura y haciéndose de vez en cuando con algún hallazgo. Permaneció tres semanas en Madrid, aunque no le gustó, pues se lamentaba de la falta de compañía sociable en la capital, que calificó de «desierto calcinado», «feo, árido, sin vegetación ni color». Sin embargo, no tardó en ser conquistado por la España monumental que fue descubriendo, cuaderno en mano, a través de un extenso itinerario que lo exponía a peligros y penurias. Hizo un buen número de apuntes y dibujos, cosa nada fácil, pues como indica el mismo Ford, desde el paso de los franceses se tenía desconfianza de todo aquel que anduviese con lápiz y cuaderno, pues podía ser considerado como informante o espía.

El libro de Ford fue muy influyente y aunque muestra prejuicios hacia los habitantes, revela una gran fascinación por ciertas ciudades antiguas y por la cultura española. Como otros viajeros en busca del pintoresquismo español se inspiró en la imagen con que Byron había descrito a Cádiz, en noviembre de 1830, y pintó una acuarela de esa bahía inscribiendo la famosa línea del canto I de la obra maestra del poeta: «Fair Cadiz rising from the dark blue sea». Dedicó veiticinco páginas de su handbook a Toledo, nueve de ellas a la gran catedral, cuyas ventanas «se encendían como esmeraldas y rubíes», a la puesta del sol. Llegó has-

${ }^{16}$ FORD Brinsley, Richard Ford in Spain, London, Wildenstein, 1974, del mismo autor Richard Ford en Sevilla, Madrid, Instituto Diego Velázquez, 1963, SUTTON Danys, en Richard Ford in Spain, «Don Ricardo, A Witty Hispanophile», 24-6. ALBERICH, José, «Richard Ford o el hispanista hispanófobo», Archivo Hispalense, clxxviii, 1975, 103-131. Ford llegó a ser una autoridad en lo tocante a la cultura española, gracias a los artículos que escribió para The Quarterly Review y otras revistas. El que dedicó a Velázquez (1843) fue el primer estudio sobre ese artista escrito en inglés. Sobre el tema ver Thomas Bean, «Richard Ford as Picture Collector and Patron in Spain», The Burlington Magazine, febrero, 1995, 96-107. 
ta Ciudad Rodrigo donde aún podian verse las huellas del sitio durante la guerra, y antes de entrar en Salamanca, que calificó de «una verdadera escuela para arquitectos», recorrió el famoso campo de batalla: «una tierra fertilizada por la sangre de los británicos que murieron por la ingrata Iberia». Iba escoltado por Francisco Sánchez, más conocido como El cojo, pues perdió una pierna en la batalla; era el mismo guía que asistió veinte años antes a Wellington y que vivía aún en los Arapiles.

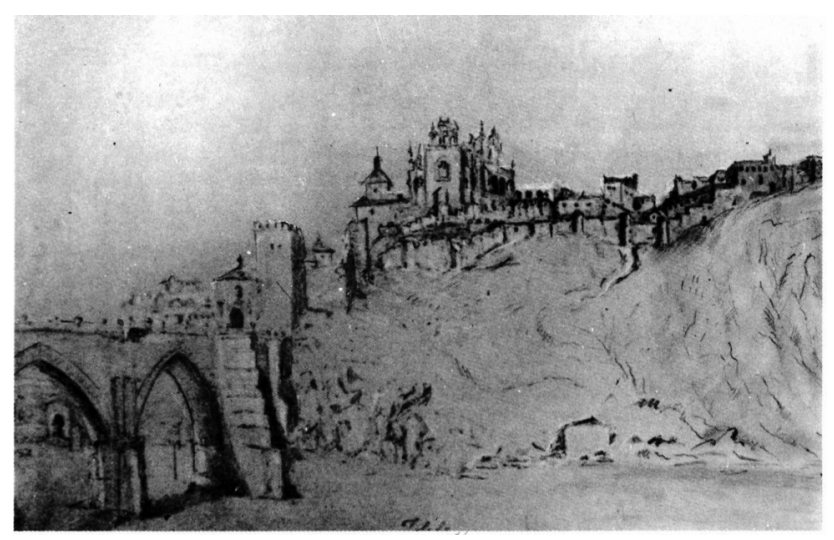

6.- Richard Ford, San Juan de los Reyes. Toledo.

Otros artistas británicos empezaron a acudir a España hacia la década de 1830, muchos de ellos animados por Tales of the Alhambra de Washington Irving, (1832), dedicada a Wilkie. ${ }^{19}$ Fue éste quien inspiró el viaje de John Frederic Lewis, que sería más tarde un afamado pintor orientalista, y fue su viaje a España, donde vivió durante dos años (1832-34), lo que cambió y maduró su manera de pintar el Cairo. De su estadía en Granada produjo Sketches and Drawings of the Alhambra (1835) con 26 litografías, con una visión completísima del monumento nazarita. Sus dibujos revelan el papel de la profusa ornamentación en el discurso geométrico y orgánico del recinto. Algunos fueron utilizados por Torres Balbás para la reconstrucción del pórtico y de la Torre del Partal. ${ }^{20}$

17 Brinsley Ford, Richrd Ford in Spain, cat. No. 105, 65. Eugène Delacroix que llegaba por mar escribió una nota que también la recuerda: «En approchant, les maisons de Cádiz blanches et dorées sur un beau ciel blue».cit. Sarah Symmons, Op. Cit., 139.

18 Cit. Ian Robertson, Op. cit., 221.

19 Blanca Krauel Heredia, Viajeros británicos en Andalucía. De Christopher Hervey a Richard Ford (1760-1845), Málaga, Universidad de Málaga, 1986.

20 Ver Tonia Raquejo, El palacio encantado. La Alhambra en el arte británico, Madrid, Taurus, 1990, Pedro A. Galera Andreu, La imagen romántica de la Alhambra, Madrid, Junta de Andalucía, El Viso, 1992. 


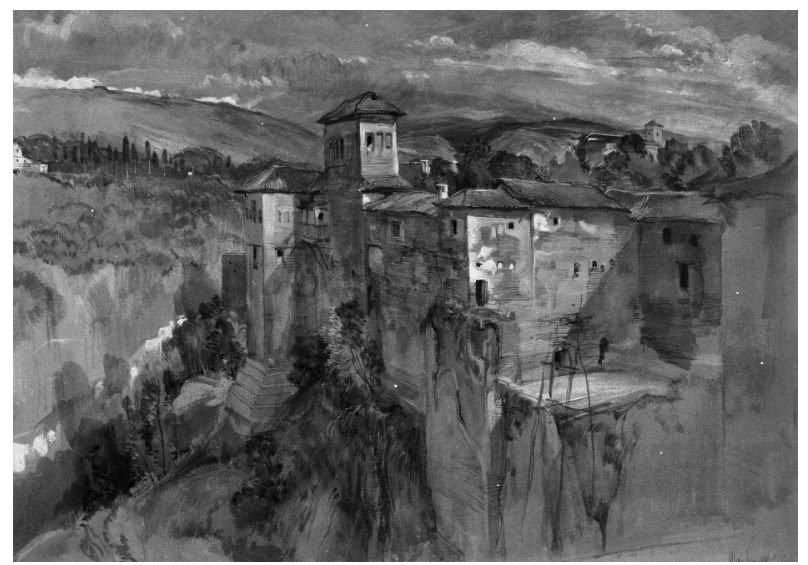

7.- John Frederick Lewis, The Alhambra, Granada, 1832, The British Museum, Londres.

Lewis fue también autor de Sketches of Spain and Spanish Character (1836), un volumen con 25 grandes litografías a doble folio con las escenas de costumbres españolas que también tomó como tema de varios cuadros. A fiesta Scene in the South of Spain, Peasants dancing the bolero (1836), es un paisaje con una pintoresca danza. Spanish fiesta tiene como motivo una corrida de toros, destaca la plaza del antiguo pueblo, con un palacio engalanado con signos religiosos, y de allí parte una calle sembrada de señoriales edificios de piedra. Posiblemente fue este fondo arquitectónico lo que entusiasmó al crítico de arte John Ruskin, y lo animó a comprar el cuadro. Inspirado por la guerra carlista, Lewis ejecutó algunos cuadros sobre este tema, estaba fascinado por la personalidad de Zumalacarregui y creía ver en esa contienda algunas similitudes con la guerra de independencia.

Los dibujos y acuarelas que Lewis hizo de la Alhambra y su paisaje ejemplifican el espíritu romántico. Es ejemplar la magnífica acuarela The Alambra, Granada, (1832), con el palacio en el escarpado monte, que se presenta en el primer plano, abruptamente, casi en escorzo ante el espectador. El pintor enfatiza la grandeza y majestad del espacio, por el ritmo de largas diagonales que lo surcan y lo unifican geográfica y culturalmente. La Torre de las Damas actua como eje direccional. Desde el ángulo inferior izquierdo, una empinada senda punteada con los tonos verdes de la vegetación lleva hasta la torre y en ángulo recto con ella, hacia la izquierda, otro vector que atraviesa la esquina superior, indica la calzada, sembrada de cipreses que va hasta el Generalife. Desde el ángulo inferior derecho, se sigue la cara lateral del edificio, hasta la torre de las Damas donde también, en ángulo hacia la derecha, una línea arbolada lleva hacia otra torre, similar en arquitectura y colorido, perteneciente a la iglesia de Santa María de la Alhambra, que fue mezquita y convertida en iglesia. Arriba, con muy alto horizonte, un cielo añil surcado por densas nubes grises. Esta visión solo se logra desde el Peinador de la Reina, el pintor se inspiró allí, lejos de la ciudad, absorto ante el altivo paisaje, permeado de silencio, para su cuadro conce- 
bido dentro de los cánones estéticos de lo sublime. Esta es la misma vista que presenta en La Alhambra y Sierra Nevada desde el Peinador de la Reina, un dibujo a lápiz de 1834. Aquí, el legendario paisaje es contemplado por una dama acodada en la galería. Esta figura no es meramente anecdótica, pues representa al espectador y al mismo pintor, e incluye símbolos de una cotidianidad transformada en universal; la siIla, el libro y el perro como fiel guardián. Otro dibujo, La Alhambra from the Alameda del Darro, incorpora la poética de las ruinas y la idea de Granada como la puerta a Oriente. En la esquina del primer plano incorpora a la vista del monumento medieval, la procesión de un entierro que sube por la vereda hasta el cementerio. Contrasta aqui primitivismo y nobleza, religiosidad cristiana y herencia islámica.

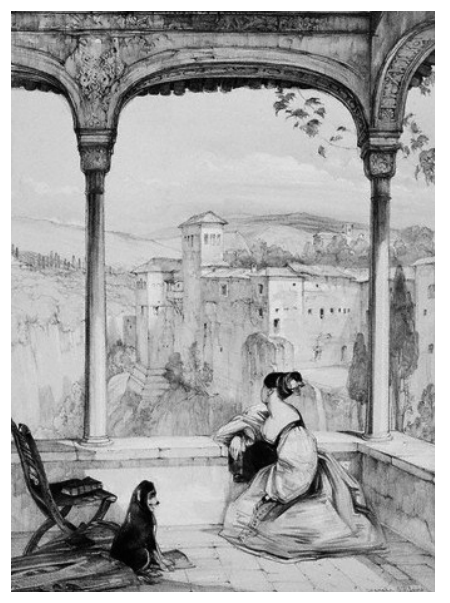

8.- John Frederick Lewis, La Alhambra y Sierra Nevada desde el Peinador de la Reina. Litografía en Sketches of Spain and Spanish Characters (1836).

9.- John Frederick Lewis, Alhambra from the Alameda del Darro, Incluida en Sketches and Drawings of the Alhambra (1835).

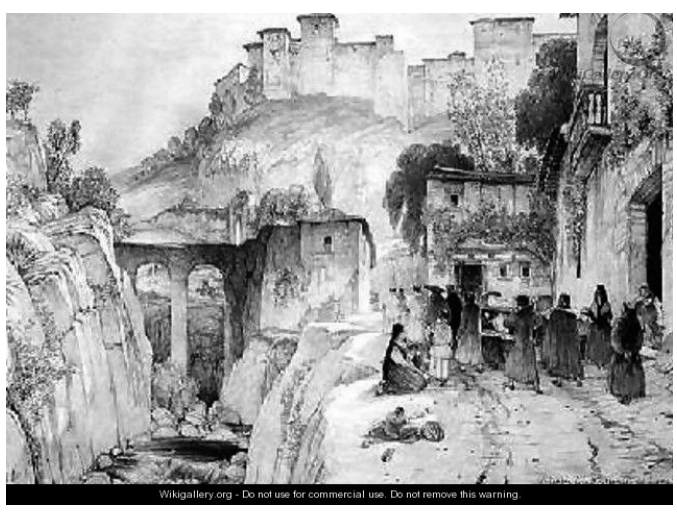

Sin duda, el más importante e influyente de los artistas británicos atraídos por el romanticismo de España fue el pintor escocés David Roberts, contemporáneo y rival de Lewis. Salió de Londres en 1832, en una aventura que duró nueve meses, y al llegar a Cádiz pronunció la frase de Byron «The city of the dark blue 
sea». ${ }^{21}$ Animado por Wilkie a sacar partido de las cualidades sublimes del paisaje español con sus pueblos y monumentos, compuso una extensa colección de vistas de Burgos, Toledo, Segovia, Córdoba, Granada, Sevilla, etc., y permaneció en Madrid durante varios meses trabajando en algunas de sus pinturas al óleo. Los dibujos y esbozos de Roberts, convertidos en grabados fueron publicados en los volúmenes de 1832 a 1836 de The Landscape Annual con un texto por el escritor Thomas Roscoe, quien también había recorrido España, y en 1837 sus dibujos fueron publicados como litografías en su Picturesque Sketches from Spain. ${ }^{22}$

Los paisajes de Roberts son muy literarios. El mismo Wilkie que lo había alentado a emprender el viaje, era admirador de Cervantes, Byron, Scott y Hartzenbusch, y comentaba en carta a Roberts que la Alhambra presentaba un reto a los pintores por todo lo que se había escrito y leído sobre ella. ${ }^{23} \mathrm{~A}$ su vez, Roberts consideraba los textos como parte esencial del paisaje, y sus cartas están llenas de imágenes literarias. Posiblemente por ello, tenía una especial habilidad en conectar las antiguas ciudades y monumentos con su pasado histórico y legendario. Además de Granada, estaba el Cádiz de Byron, la ciudad del «dark blue sea», ante la cual el artista comentaba: «encuentro todo lo que han escrito los viajeros y todo lo que los poetas imaginaron». No deja de expresar su impresión sobre «el corazón romántico del paisaje español». Considera que Córdoba «para el anticuario y el artista» son ricos más allá de toda medida, sus tesoros se encuentran «en las torres y en los pilares», que dibujó abundantemente, escribía: «mi portafolio se está enrqueciendo, ...aún tengo seis torres», ${ }^{24}$ y toda su estancia en Andalucía fue muy fecunda, llegó con gran cantidad de dibujos de edificios y fascinantes vistas de ciudades.

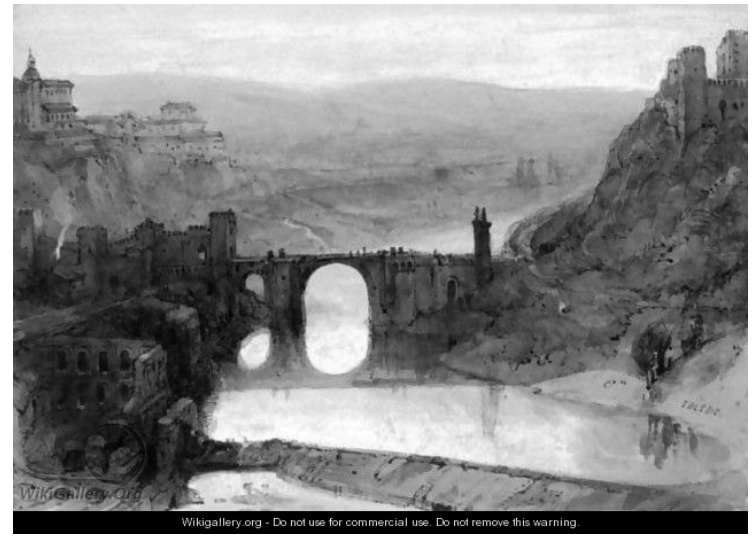

10.- David Roberts, El Puente de San Martín de Toledo. En Thomas Roscoe,

\footnotetext{
21 SIM Katherine, David Roberts R.A. 1796-1864, A Biography, Londres, Quartet Books, 1984.

22 Picturesque Sketches from Spain taken during the years 1832-1833, London, Hodgson and Graves 1836-37

${ }^{23}$ cit. por ROBERTS David en carta fechada I 2 de marzo de 1833, fol 56, National Library of Scotland, Ms. 3521, fol. 56., cit., Symmons, Op. cit., 142.

24 Ibid., 142
} 
Jenning's Landscape Annual, for Andalusia, Londres, 1835, vol. I, p. 162.

Roberts había sido escenógrafo en Edimburgo y ello explica las características teatrales de sus vistas. Su experiencia como autor de escenarios, panoramas y dioramas le servía para estilizar sus paisajes, pues quería que inspiraran asombro y admiración. Para obtener un efecto visual dramático, sacrificaba la exactitud, alteraba las proporciones y los ángulos, y manejaba habilmente las luces y las sombras. Escogía sus puntos de vista muy cuidadosamente. Por ejemplo decidió que el dramático emplazamiento de Ronda, colgada sobre el río, se veía mejor desde lejos, y en otro dibujo, el puente que une a las dos partes de la ciudad se ve desde abajo para enfatizr la altura del cañón. En una magnífica acuarela, el Puente de San Martín de Toledo une las dos montañas rocosas y marciales y duplica el puente en su reflejo en el río. Contemplaba algunos monumentos, mucho más cerca, como en su ambicioso Interior de la catedral de Sevilla (1833), pintado in situ durante el festival de Corpus Christi, con el recinto lleno de gente y profusamente iluminado. The Fortress of the Alhambra fue una de sus obras más difundidas, ilustra lo que Granada significaba para los viajeros ingleses: la culminación de un viaje iniciático y la puerta a Oriente. La Torre de Comares muestra también la intensificación del dramatismo por el enfoque de abajo a arriba y el juego con la luz y las sombras. En Torre de los siete suelos con dos pequeñas figuras humanas que contemplan las ruinas del edificio, vestigio del magnífico pasado. La ambientación nocturna colabora al sentimiento elegíaco.

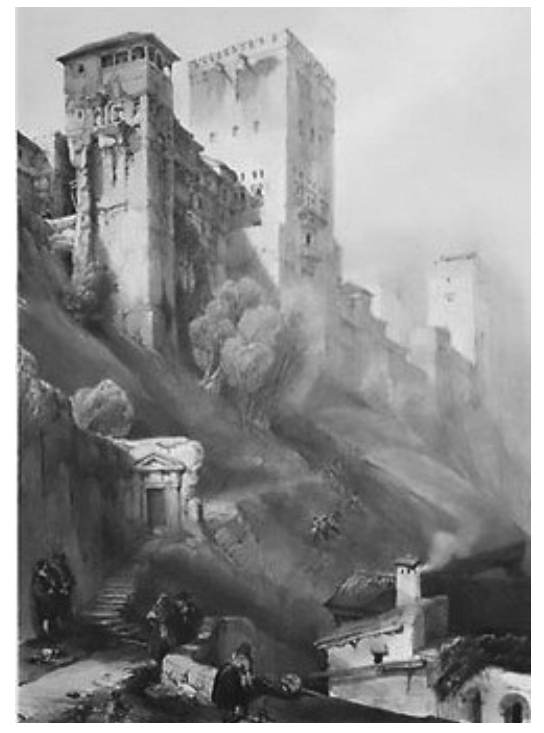

11.- David Roberts, Torre de Comares en Thomas Roscoe,

The Tourist in Spain, Robert Jennings \& Co., Londres, 1835.

Finalmente, los británicos, hasta cierto punto, ayudaron a los románticos españoles a descubrir su propio paisaje. Roberts influyó a varios artistas españoles, 
y entre ellos a Jenaro Pérez Villamil a quien conoció en Sevilla. El artista gallego, se había formado en una tradición topográfica del paisaje, dedicado a la escenografía y había residido un tiempo en Cádiz, lugar frecuentado por ingleses, por lo que se explica su inmediata afinidad por Roberts. Se sabe que poseía Picturesque Sketches in Spain, que hasta cierto punto lo inspiraron para su España artística y monumental, una serie de litografías con iconografía de la España medieval. Fue publicada en Paris, en tres volúmenes entre 1842 y 1844, vendiéndose los 1200 ejemplars en solo dos meses. ${ }^{25}$

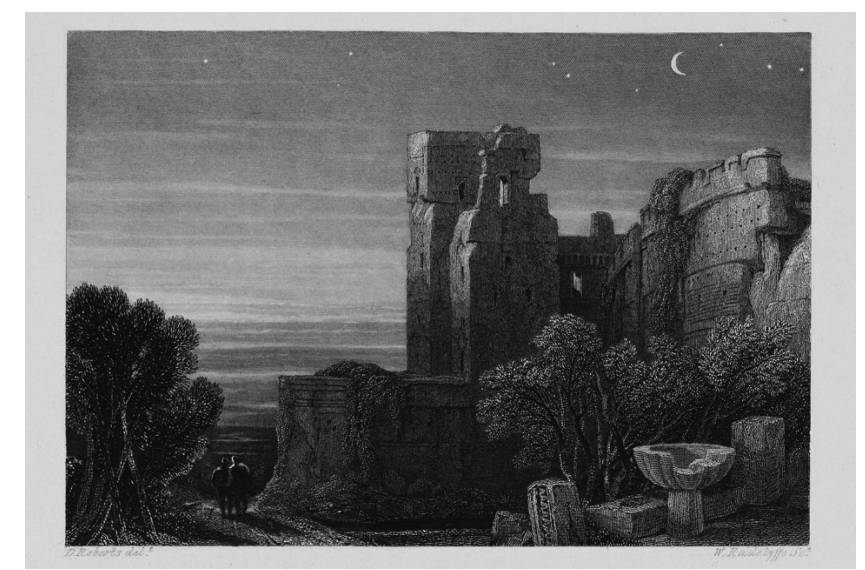

12.- David Roberts, Tower of the Seven Vaults. (Torre de los Siete Suelos), Incluida en Roscoe, Thomas, The Tourist in Spain.

La próximidad de Villaamil a Roberts y, a través de éste, a Turner, se hace aún más patente en sus cuadros, donde utiliza recursos compositivos que habían empleado los dos artistas británicos, como los haces de luz del sol poniente que iluminan la roca sobre la que se asientan las ruinas de un castillo. Interesa también saber que Turner cultivó el motivo del castillo en una colina o montaña, dominando un paisaje, y a veces reflejado en un curso de agua. Perez Villaamil abordó varias veces este tema,y se sabe que conservaba algunos grabados de obras de Turner. De este modo, a diferencia de otros paisajistas españoles, cercanos al paisaje holandés y flamenco del siglo XVII, se familiarizó con el paisajismo británico de su tiempo.

Una de las obras más desatacadas de Villaamil es El Castillo de Gaucín un paraje situado en la provincia de Málaga. Este cuadro es similar a la conocida ilustración de Roberts Gaucin Looking Towards Gibraltar and the Coast of Bar-

25 SYMMONS Sarah, "A new people and a Limited Society: British Art and the Spanish Spectator», en ed. Christiana Payne and William Vaughan, English Accents. Interactions with British Art c. 1776 1855, Burlington Vt., Ashgate Publishing Limited, 2004, 101-124. Cit. 114. 
bary. ${ }^{26}$ Ambas obras tienen la misma composición y estructura, el mismo punto de vista. A la derecha el fantástico Castillo elevándose sobre una roca, con las sierras de Casares y camino de Gibraltar por la izquierda; torre albarrana en un monte de menor altura en el centro; fondo con el Peñón de Gibraltar, el Estrecho y las montañas africanas. ${ }^{26}$

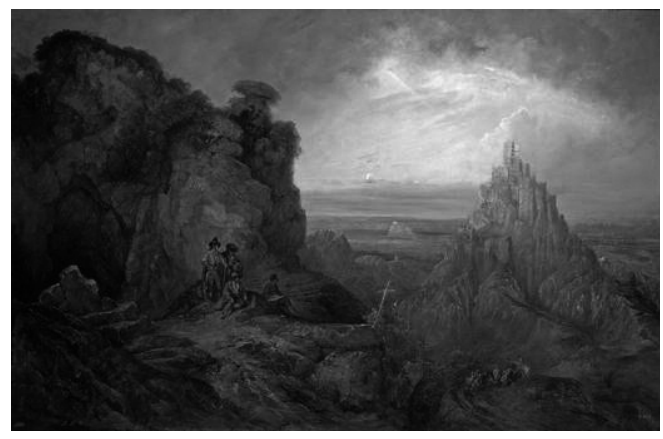

13.- Jenaro Pérez Villaamil. Castillo de Gaucín, 1849, Museo del Prado,

14.- David Roberts, Castillo de Gaucín, 1833, en Roscoe, The Tourist in Spain, 1835

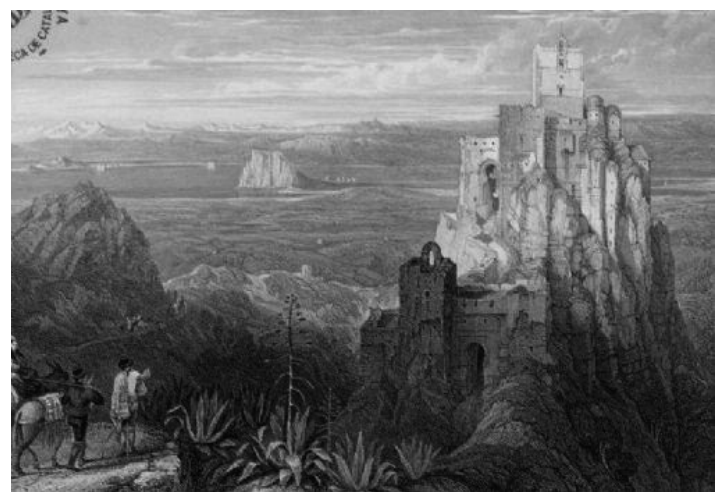

En 1835 Villaamil obtuvo la cátedra de paisaje en la Real Academia de San Fernando, de la que sería director.

26 Aureliano de Beruete señalaba que sería interesante hacer la comparación entre Villaamil y «un gran artista inglés, hoy de renombre universal, Turner». La celebración en 1935 e3 una exposición de Roberts en el Museo de Arte Moderno volvió a plantear la relación entre Turner y Vallaamil a través de Roberts, así lo hizo Gutiérrez Abascal (Juan de la Encina). http://www.museodelprado.es/pradomedia/.Sobre este tema ver también ARIAS ANGLÉS Enrique, El paisajista romántico Jenaro Pérez Villaamil, Madrid, Centro de Estudios Históricos, 1986, y Teodoro de Molina, «Apuntes de la historia del Castillo de Gaucín», www.gaucin.tv/otras/otras17.htm. 